\title{
Leveraging elasticity to uncover the role of Rabinowitsch suspension through a wavelike conduit
}

\author{
SARA ABDELSALAM ${ }^{1}$ and A Zaher ${ }^{2}$ \\ ${ }^{1}$ Universidad Nacional Autónoma de México Campus Juriquilla \\ ${ }^{2}$ Benha University
}

October 5, 2020

\begin{abstract}
The present work presents a mathematical investigation of a Rabinowitsch suspension fluid through elastic walls with heat transfer under the effect of electroosmotic forces (EOFs). The governing equations contain empirical stress-strain equations of Rabinowitsch fluid model, equations of fluid motion along with heat transfer. It is of interest in this work to study the effects of EOFs, rigid spherical particles which are suspended in the Rabinowitsch fluid, Grashof parameter, heat source and elasticity on the shear stress of Rabinowitsch fluid model and flow quantities. The solutions are achieved by taking long wavelength approximation with creeping flow system. A comparison is set between the effect of pseudoplasticity and dilatation on the behaviour of shear stress, axial velocity and pressure rise. Physical behaviours have been graphically discussed. It was found that the Rabinowitsch and electroosmotic parameters enhance the shear stress while they reduce the pressure gradient. The present analysis is particularly important in biomedicine and physiology.
\end{abstract}

\section{Leveraging elasticity to uncover the role of Rabinowitsch suspen- sion through a wavelike conduit}

Sara I. Abdelsalam ${ }^{1,2, *}$ and A. Z. Zaher ${ }^{3}$

${ }^{1}$ Instituto de Matemáticas - Juriquilla, Universidad Nacional Autónoma de México, Blvd. Juriquilla 3001, Querétaro 76230, México

${ }^{2}$ Basic Science, Faculty of Engineering, The British University in Egypt, Al-Shorouk City, Cairo 11837, Egypt

${ }^{3}$ Engineering Mathematics and Physics Department, Faculty of Engineering, Shubra-Benha University, Egypt.

Email: abdullah.zaher@feng.bu.edu.eg

Abstract: The present work presents a mathematical investigation of a Rabinowitsch suspension fluid through elastic walls with heat transfer under the effect of electroosmotic forces (EOFs). The governing equations contain empirical stress-strain equations of Rabinowitsch fluid model, equations of fluid motion along with heat transfer. It is of interest in this work to study the effects of EOFs, rigid spherical particles which are suspended in the Rabinowitsch fluid, Grashof parameter, heat source and elasticity on the shear stress of Rabinowitsch fluid model and flow quantities. The solutions are achieved by taking long wavelength approximation with creeping flow system. A comparison is set between the effect of pseudoplasticity and dilatation on the behaviour of shear stress, axial velocity and pressure rise. Physical behaviours have been 
graphically discussed. It was found that the Rabinowitsch and electroosmotic parameters enhance the shear stress while they reduce the pressure gradient. The present analysis is particularly important in biomedicine and physiology.

Keywords: Elasticity; electroosmotic forces; heat transfer; Rabinowitsch fluid; suspension

\section{Introduction}

The movement of blood liquids is an important study for the mathematical simulation of medical applications. Rabinowitsch fluid is one of the fluids that simulate blood movement because the Rabinowitsch model effectively relies on studying the result of lubricant additives, for a wide range of shear rates, and studying their experimental data. Over the past decades, scientists have made active efforts to increase the ability of solidifying the features of non-Newtonian lubricants using long-chain quantities by adding a very small addition of the polymer solution. A very important result from this is that this result reduces the lubricant sensitivity. Additionally, a non-linear relationship appears between the shear stress rate and shear pressure. Through those recent actions based on the Rabinowitsch model, Akbar and Butt [1] studied the flow of the Rabinowitsch model due to the cilia located on the wall. Also, Singh et al . [2] studied the movement of Rabinowitsch fluid through peristaltic flow. In addition, Vaidya [3] investigated the movement of Rabinowitsch fluid through the oblique wall of a channel, while Sadaf and Nadeem [4] studied the Rabinowitsch model through a non-uniform conduit with peristalsis. Choudhari et al . [5] also studied the effect of slipping on the oscillating transmission of a Rabinowitsch model in a non-uniform channel.

In recent years, microfluidic systems have been developed through the use of Electric- Double-Layer (EDL). This increased interest is reflected in references [6-8]. Electrical osmosis is defined as the movement of a liquid in relation to a fixed surface due to the presence of an externally applied electric field. Among the first studies that have studied the application of these external forces goes back to Ross [9]. The idea of electrical ripening comes into contact with the aqueous electrolytic solution with the solids and then generates a relatively electrical charge. In addition, the opposite ion charge is attracted to that charge on the surface and the opposite process from the ions on the surface and shows the double layer, and thus the surface becomes electrically charged. As a result of this phenomenon, a process of acceleration of the liquid by migrating ions occurs and the resulting flow is called electromagnetic flow.

The study of the movement of suspended impurities inside the fluid is considered the most important medical application. The movement of the fluid that contains impurities is similar to the movement of the blood plasma, because the blood consists of solid materials in addition to that it is a liquid in which those substances swim. In that sense, there are a lot of species studied such as sickle cell (Hb SS), plasma cell dyscrasias, normal blood, controlled hypertension, uncontrolled hypertension and polycythemia. Each of these types is known with a specific high order size, i.e. $C=0.248, C=0.28, C=0.426, C=0.4325, C=0.4331$ and $C$ $=0.632[10]$. In addition, the study of the movement of suspended impurities inside fluids is very interesting because they resemble white blood cells, red blood cells and/or platelets that move inside the blood. Many experimental and analytical studies have focused on studying suspended impurities because of their great importance in improving and understanding the flow of blood flow and the distribution of proteins within it [11-13].

The geometrical shape of fluid flow has an important role in understanding various properties of different fluid flows such as blood flow and other important applications. Most studies that have discussed fluid movement have relied on solid ducts and tubes [14-20]. Because biological flows depend on their flexible flow fields, and this appears through their flexible nature, so the flow and the movement of Newtonian and non-Newtonian fluids through walls of a flexible nature carry many important medical applications such as blood flow through the arteries, small blood vessels, heart systems and others which, according to some studies, revealed that the velocity of the blood is greatly affected by the elastic placement of the walls. Some of the work that have been interested in discussing the flow rate through elastic nature can be found in the refs. [21-24].

Accordingly, this work attempts to fill the void of the movement of the particulate suspension under the 
effects of electroosmotic forces using Rabinowitsch fluid. Analytical solution is used to obtain the physical parameters of the problem subjected to appropriate boundary conditions. The impact of relevant parameters is discussed graphically.

\section{Non-Newtonian Rabinowitsch fluid equation}

The isotropic rheological equation of a Rabinowitsch fluid takes the following form:

$$
\tau_{X Y}+\mu_{o} \tau_{X Y}^{3}=\mu_{S}(C) \frac{\partial U}{\partial Y}
$$

where the coefficient $\mu_{o}$ represents pseudo-plasticity of the fluid which takes a fundamental role in determining the nature of fluids, and $C$ is the volume fraction. The model represents a pseudoplastic state for $\mu_{o}>0$, a Newtonian state for $\mu_{o}=0$ and an expanded fluid model for $\mu_{S}<1$.

\section{Mathematical model}

Consider a particulate suspension swimming in a Rabinowitsch fluid through elastic peristaltic walls of a channel of which amplitude $a$ and half width $b$. In addition, consider that the deformation on the wall is $\alpha$ as shown inFig 1 . Also, the inlet pressure is defined as $p_{i}$ and the outlet pressure is defined as $p_{o}$ are shown in Fig 1 . The effect of the electroosmotic forces on the Rabinowitsch fluid through the elastic peristaltic walls is taken into account. The velocity of the particulate suspension and Rabinowitsch fluid are denoted by $\vec{V}\left(U_{p}, V_{p}\right), \vec{V}\left(U_{f}, V_{f}\right)$. The mathematical geometry of the channel wall is given by

$H(X, t)= \pm\left(d+a \sin \frac{2 \pi}{\lambda}(X-c t)\right)$,

Here, $d$ is the radius of the artery channel, $a$ is the amplitude of the wall, $\lambda$ is the amplitude of the peristaltic wave and $c$ be the blood velocity.

(a) (b)
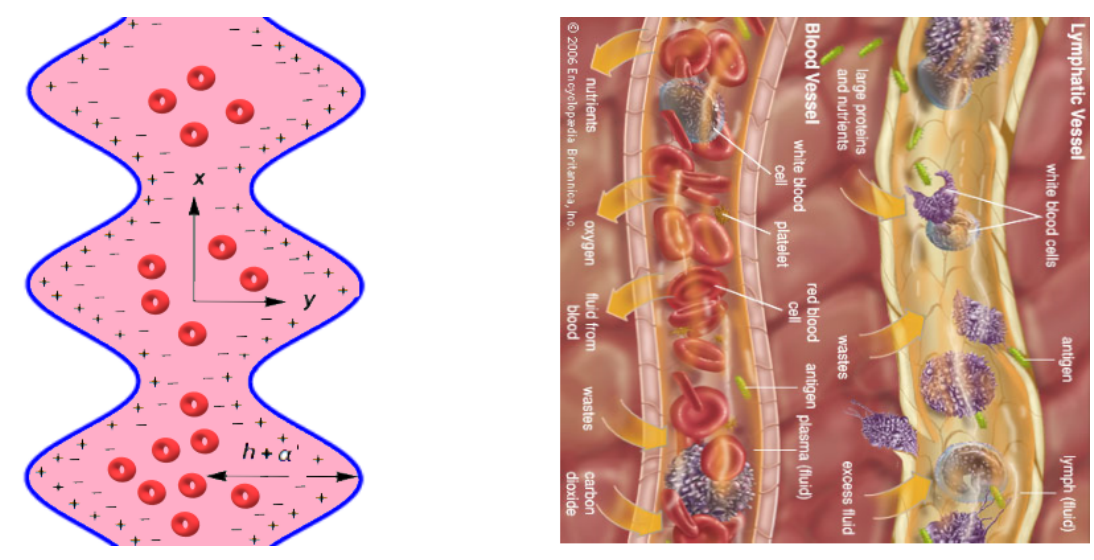

Figure 1: Physical modeling of problem

The momentum and continuity equations for the problem of both particle and fluid phases are given in the following form [25]: 


\section{Model of Fluid Phase}

$$
\begin{gathered}
\frac{\partial U_{f}}{\partial X}+\frac{\partial V_{f}}{\partial Y}=0 \\
\rho_{f} C_{\mathrm{PH}}\left(\frac{\partial U_{f}}{\partial t}+U_{f} \frac{\partial U_{f}}{\partial X}+V_{f} \frac{\partial U_{f}}{\partial Y}\right) \\
=-C_{\mathrm{PH}} \frac{\partial P}{\partial X}+C_{\mathrm{PH}}\left[\frac{\partial \tau_{X X}}{\partial X}+\frac{\partial \tau_{X Y}}{\partial Y}\right]+\rho_{e} E_{x}+\rho \gamma g\left(T-T_{0}\right)-C S\left(U_{f}-U_{P}\right), \\
\rho_{f} C_{\mathrm{PH}}\left(\frac{\partial V_{f}}{\partial t}+U_{f} \frac{\partial V_{f}}{\partial X}+V_{f} \frac{\partial V_{f}}{\partial Y}\right)=-C_{\mathrm{PH}} \frac{\partial P}{\partial Y}+C_{\mathrm{PH}}\left[\frac{\partial \tau_{Y X}}{\partial X}+\frac{\partial \tau_{Y Y}}{\partial Y}\right]-C S\left(V_{f}-V_{P}\right), \\
\left(\rho^{\mathrm{c})}\right)_{f}\left(\frac{\partial T_{f}}{\partial t}+U_{f} \frac{\partial T_{f}}{\partial X}+V_{f} \frac{\partial T_{f}}{\partial Y}\right)=k\left(\frac{\partial^{2} T}{\partial X^{2}}+\frac{\partial^{2} T}{\partial Y}\right)+H_{S},
\end{gathered}
$$

\section{Model of Particle Phase}

$$
\begin{gathered}
\frac{\partial U_{P}}{\partial X}+\frac{\partial V_{P}}{\partial Y}=0, \\
\rho_{P} C_{\mathrm{PH}}\left(\frac{\partial U_{P}}{\partial t}+U_{P} \frac{\partial U_{P}}{\partial X}+V_{P} \frac{\partial U_{P}}{\partial Y}\right)=-C_{\mathrm{PH}} \frac{\partial P}{\partial X}+C S\left(U_{f}-U_{P}\right), \\
\rho_{f} C_{\mathrm{PH}}\left(\frac{\partial V_{P}}{\partial t}+U_{P} \frac{\partial V_{P}}{\partial X}+V_{P} \frac{\partial V_{P}}{\partial Y}\right)=-C_{\mathrm{PH}} \frac{\partial P}{\partial Y}+C S\left(V_{f}-V_{P}\right),
\end{gathered}
$$

where $C_{\mathrm{PH}}=1-C, S$ is the drag coefficient and $\mu_{S}(C)$ is the viscosity of suspension. The empirical relation for $S$ and $\mu_{S}(C)$ can be described as

$$
\begin{gathered}
\mu_{S}=\frac{1}{(1-m C)}, \quad m=0.07 * \operatorname{Exp}\left[2.49 * C-\frac{1107}{273} * \operatorname{Exp}[-1.69 * C]\right], \\
S=\frac{9 \mu_{0}}{2 \in^{2}} \gamma(C), \quad \gamma(C)=\frac{4+3 \sqrt{8 C-3 C^{2}}+3 C}{(2-3 C)^{2}} .
\end{gathered}
$$

Here, $\mu_{0}$ is the viscosity of fluid for suspending medium, $\in$ is the radius of a particle.

Now, we use the convenient transformation to convert from fixed frame to wave frame as follows:

$$
x=X-c t, \quad y=Y, \quad u=U-c, \quad p=P .
$$

Then, the mathematical formulation and Rabinowitsch fluid equations (2-9) take the following form:

\section{Rabinowitsch fluid equations}

$$
\tau_{x y}+\mu_{o} \tau_{x y}^{3}=\mu_{s}(C) \frac{\partial u_{f}}{\partial y}
$$


Model of fluid phase

$$
\begin{gathered}
\rho_{f} C_{\mathrm{PH}}\left(u_{f} \frac{\partial u_{f}}{\partial x}+v_{f} \frac{\partial u_{f}}{\partial y}\right) \\
=-C_{\mathrm{PH}} \frac{\partial p}{\partial x}+C_{\mathrm{PH}}\left[\frac{\partial \tau_{x x}}{\partial x}+\frac{\partial \tau_{x y}}{\partial y}\right]+\rho_{e} E_{x}+\rho \gamma g\left(T-T_{0}\right)-C S\left(u_{f}-u_{P}\right), \\
\rho_{f} C_{\mathrm{PH}}\left(u_{f} \frac{\partial V_{f}}{\partial x}+v_{f} \frac{\partial v_{f}}{\partial y}\right)=-C_{\mathrm{PH}} \frac{\partial p}{\partial y}+C_{\mathrm{PH}}\left[\frac{\partial \tau_{y x}}{\partial x^{2}}+\frac{\partial \tau_{y y}}{\partial y^{2}}\right]-C S\left(v_{f}-v_{P}\right), \\
\left(\rho^{\mathrm{a}}\right) f_{f}\left(\frac{\partial T_{f}}{\partial t}+u_{f} \frac{\partial T_{f}}{\partial x}+v_{f} \frac{\partial T_{f}}{\partial y}\right)=k\left(\frac{\partial^{2} T}{\partial x^{2}}+\frac{\partial^{2} T}{\partial y^{2}}\right)+H_{S},
\end{gathered}
$$

Model of particle phase

$$
\begin{aligned}
& \rho_{P} C_{\mathrm{PH}}\left(u_{P} \frac{\partial u_{P}}{\partial x}+v_{P} \frac{\partial u_{P}}{\partial y}\right)=-C_{\mathrm{PH}} \frac{\partial p}{\partial x}+C S\left(u_{f}-u_{P}\right), \\
& \rho_{f} C_{\mathrm{PH}}\left(u_{P} \frac{\partial v_{P}}{\partial x}+v_{P} \frac{\partial v_{P}}{\partial y}\right)=-C_{\mathrm{PH}} \frac{\partial p}{\partial y}+C S\left(v_{f}-v_{P}\right)
\end{aligned}
$$

\section{Electroosmotic flow}

the Poisson-Boltzmann equation:

$$
\nabla^{2} \varphi=\frac{\rho_{e}}{\epsilon}
$$

where $\rho_{e}$ be a charge density, $\epsilon$ is the electric permittivity and $\varphi$ is the electroosmotic potential function. The charge density $\rho_{e}$ of the fluid in a unit volume is given by:

$\rho_{e}=\varepsilon e\left(n^{+}-n^{-}\right)=-2 \varepsilon e n_{0} \sinh \left\{\frac{\varepsilon \varepsilon \varphi}{2}\right.$

$\operatorname{englishk}_{B} T_{\mathrm{av}}$,

$$
n^{-}=n_{0} \text { selectlanguagegreeke } \frac{\frac{\mathrm{e} \varphi}{k_{B} T_{\mathrm{av}}}}{n^{+}}=n_{0} e^{\frac{-\varepsilon e \varphi}{k_{B} T_{\mathrm{av}}},},
$$

where $\varepsilon, n^{+}, n^{-}, e, k_{B}$, and $\mathrm{T}_{\mathrm{av}}$ are the valence of ions, the number densities of positive and negative ions, electric charge, Boltzmann's constant, local absolute temperature of the electrolytic solution and bulk volume concentration of positive or negative ions, respectively. In addition, using the Debye-Huckel linearization principle $\left\{\frac{\varepsilon \varepsilon \varphi^{\prime}}{p}\right.$

englishk $_{B} T_{\text {av }} \ll 1$. Eq. (19) reduces to

$$
\rho_{e}=\frac{-\epsilon}{\Gamma^{2}} \varphi
$$


where $\Gamma=(\varepsilon \varepsilon)^{-1} \sqrt{\frac{k_{B} T_{\alpha}}{2 n_{0}}}$ is the Debye-Huckel parameter which describes the properties of the EDL thickness. The solution for the distribution of the electroosmotic potential can easily be achieved using the Poisson-Boltzmann equation:

$$
\frac{\partial^{2} \varphi}{\partial x^{2}}+\frac{\partial^{2} \varphi}{\partial y^{2}}=\frac{1}{\Gamma^{2}} \varphi
$$

\section{Non-dimensional physical parameters}

The non dimensionless quantities are introduced in the following expression

$$
\begin{gathered}
u_{P, f}=\frac{u_{P, f}}{c}, y=\frac{y}{a}, \mathrm{v}_{P, f}=\frac{v_{P, f}}{\delta \varsigma}, p=\frac{a^{2}}{\lambda \varsigma \mu_{o}} p, \delta=\frac{a}{\lambda}, \vartheta=\frac{\varphi}{\zeta}, R e=\frac{\rho_{f} \mathrm{c} \mathrm{a}}{\mu_{0}}, \\
G r=\underline{\rho_{f} \curlyvee \curlyvee a^{2} T_{0}}
\end{gathered}
$$

english $\mu_{o} \mathrm{c}, \theta=\frac{T-T_{0}}{T_{0}}, \mu=\frac{\mu_{s}(C)}{\mu_{0}}, \tau=\frac{a}{c \mu_{0}} \tau, U_{\mathrm{HS}}=-\frac{E_{x}}{\mu_{0} \mathrm{c}}$,

$$
\begin{gathered}
K=\frac{\mu_{S}(C) c^{2} \mu_{0}^{2}}{a^{2}}, m=\frac{a}{k^{2}}, M=\frac{S a^{2}}{\mu_{S}(C)(1-C)}, Q=\frac{H_{s} a^{2}}{\mu_{0} T_{o}}, p_{r}=\frac{\mu_{o} C_{f}}{k}, \\
h=\frac{H}{d}, \phi=\frac{a}{d}
\end{gathered}
$$

where $K, m, Q, p_{r}, U_{\mathrm{HS}}, G r, R e$ are, respectively, the Rabinowitsch fluid parameter, electroosmotic parameter, heat source, Prandtl number, electroosmotic velocity, Grashof number and Reynolds number. The non-dimensional formulation of mathematical geometry for the channel wall is given by

$$
h(x)= \pm(1+\phi \sin 2 \pi x)
$$

where $\phi$ is the amplitude ratio.

After using the non-dimensional physical parameters given by Eq. (23) in the governing Eqs. (12-17) and in Eq. (22), we find

\section{Non-dimensional Rabinowitsch fluid equations}

$$
\tau_{\mathrm{xy}}+K \tau_{\mathrm{xy}}{ }^{3}=\mu \frac{\partial u_{f}}{\partial y}
$$

\section{Non-dimensional model of fluid phase}

$R_{e} \delta C_{\mathrm{PH}}\left(u_{f} \frac{\partial u_{f}}{\partial x}+v_{f} \frac{\partial u_{f}}{\partial y}\right)=-C_{\mathrm{PH}} \frac{\partial p}{\partial x}+C_{\mathrm{PH}}\left[\delta \frac{\partial \tau_{\mathrm{xx}}}{\partial x}+\frac{\partial \tau_{\mathrm{xy}}}{\partial y}\right]+m^{2} U_{\mathrm{HS}} \cosh \mathrm{my}+G_{r}\left(T-T_{0}\right)-C C_{\mathrm{PH}} \mu \mathrm{M}\left(u_{f}-u_{P}\right)$

$R_{e} \delta C_{\mathrm{PH}}\left(u_{f} \frac{\partial v_{f}}{\partial x}+v_{f} \frac{\partial v_{f}}{\partial y}\right)=-C_{\mathrm{PH}} \frac{\partial p}{\partial y}+C_{\mathrm{PH}}\left[\frac{\partial \tau_{\mathrm{yx}}}{\partial x}+\frac{\partial \tau_{\mathrm{yy}}}{\partial y}\right]-C C_{\mathrm{PH}} \mu \mathrm{M}\left(v_{f}-v_{P}\right)$, 


$$
R_{e} p_{r} \delta\left(u_{f} \frac{\partial \theta}{\partial x}+v_{f} \frac{\partial \theta}{\partial y}\right)=\left(\frac{\partial^{2} \theta}{\partial x^{2}}+\frac{\partial^{2} \theta}{\partial y^{2}}\right)+Q
$$

Non-dimensional model of particle phase

$$
\begin{aligned}
& \frac{\rho_{P}}{\rho_{f}} \mathrm{C} R_{e} \delta\left(u_{P} \frac{\partial u_{P}}{\partial x}+v_{P} \frac{\partial u_{P}}{\partial y}\right)=-C \frac{\partial p}{\partial x}+C C_{\mathrm{PH}} \mu \mathrm{M}\left(u_{f}-u_{P}\right) \\
& \frac{\rho_{P}}{\rho_{f}} \mathrm{C} R_{e} \delta\left(u_{P} \frac{\partial v_{P}}{\partial x}+v_{P} \frac{\partial v_{P}}{\partial y}\right)=-C \frac{\partial p}{\partial y}+C C_{\mathrm{PH}} \mu \mathrm{M} \delta\left(v_{f}-v_{P}\right)
\end{aligned}
$$

with dimensionless boundary conditions

$$
\begin{array}{ccc}
u=-1, & \theta=0, \quad \vartheta=1 \text { at } & y=h(x), \\
u=-1, \quad & \theta=0, \quad \vartheta=1 \quad \text { at } \quad & y=-h(x) \\
& & \\
& & \tau_{\mathrm{xy}}=0 \text { at } y=0 .
\end{array}
$$

\section{Methodology}

Taking a long wavelength approximation and a creeping flow system, i.e. $\delta \ll 1$, the solution of Eqs. (24-29) takes the following form

$$
\begin{aligned}
& \theta(y)=\frac{1}{2} Q(h-y)(h+y) \\
& \tau_{\mathrm{xy}}=\frac{6 \frac{\partial p}{\partial x} y+G_{r} \mathrm{Q} \mathrm{y}\left(-3 h^{2}+y^{2}\right)-6 m U_{\mathrm{HS}} \frac{\sinh (m y)}{\cosh (m h)}}{6 \mathrm{C}_{\mathrm{PH}}} \\
& u(y)=\frac{1}{8640 \mu m^{6} C_{\mathrm{PH}}^{3}}\left\{m ^ { 6 } \left\{-8640 \mu C_{\mathrm{PH}}^{3}+4 K \mathrm{Q}^{3} y^{10} \mathrm{G}_{r}^{3}+1080 y^{2}\left(-3 K m^{2} U_{\mathrm{Hs}}^{2} \operatorname{Sech}^{2}(h(x) m)+2 C_{\mathrm{PH}}^{2}\right)\left(2 \frac{\mathrm{dp}}{\mathrm{dx}}-h^{2} C\right.\right.\right.
\end{aligned}
$$

\section{Theoretical determination of pressure gradient and pressure rise application in blood flows}

In this section, the deformation in the walls, that is defined by elasticity in the channel walls, is taken into account which appears from the pressure shown in Fig. 1 . According to Rubinow and Keller [22], the flow rate and pressure gradient are related by the following expression:

$Q=-\sigma\left(p_{i}-p_{o}\right) \frac{\partial p}{\partial x}$,

The flow rate is defined as

$$
Q=\int_{0}^{h} u(y) \mathrm{dy}
$$

Following the hypothesis of elastic walls, according to Rubinow and Keller [24], and using Eqs. (33-35), it is found that the flow rate takes the following form as follows

$$
Q=\sigma_{1}\left(p_{i}-p_{o}\right)\left(-\frac{\partial p}{\partial x}\right)^{3}+\sigma_{2}\left(p_{i}-p_{o}\right)\left(-\frac{\partial p}{\partial x}\right)^{2}+\sigma_{3}\left(p_{i}-p_{o}\right)\left(-\frac{\partial p}{\partial x}\right)+\operatorname{constant}(36)
$$




$$
\begin{aligned}
& \text { where } \sigma_{1}\left(p_{i}-p_{o}\right)=\frac{\alpha(x)^{5} k}{5 A \mathrm{M}^{3}},(37) \\
& \sigma_{2}\left(p_{i}-p_{o}\right)=\frac{1}{8640 \mu \mathrm{m}^{6} M^{3}}\left(\frac{13824}{7} G_{r} \alpha(x)^{7} \mathrm{~K} m^{6} Q+103680 \alpha(x) \mathrm{K} m^{4} U_{\mathrm{HS}}+25920 \alpha(x) \mathrm{K} m^{4}\left(2+\alpha(x)^{2} m^{2}\right) U h s-1\right. \\
& \sigma_{3}\left(p_{i}-p_{o}\right)=\frac{1}{8640 \mu m^{6} M^{3}}\left(-2880 \text { selectlanguagegreek }(x)^{3} m^{6} M^{2}-\frac{5312}{7} G_{r}{ }^{2} \alpha(x)^{9} K m^{6} Q^{2}+4320(x)^{3} K m^{8} U_{\mathrm{HS}^{2}}(\alpha(x) m)\right. \\
& \text { Constant }=\frac{1}{8640 \mu m^{6} M^{3}}\left\{-8640 \mu \mathrm{h}(x) m^{6} M^{3}+1152 G_{r} h(x)^{5} m^{6} M^{2} Q+\frac{7552}{77} G_{r}^{3} h(x)^{11} \mathrm{~K} m^{6} Q^{3}-1728 c 1^{2} G_{r} h(x)^{5} K \mathrm{~m}^{8}\right.
\end{aligned}
$$

Here, $\alpha(x)=h(x)+\alpha^{\prime}$, whereh $(x)$ and $\alpha^{\prime}$ are the radii of the channel for peristalsis and elasticity, respectively. Also, the pressure rise is defined as

$p=\int_{0}^{1}\left(\frac{\mathrm{dp}}{\mathrm{dx}}\right) \mathrm{dx} \cdot(41)$

8 Graphical results and discussion

The goal of this section is to study the effect of the pertinent parameters on the resulted physical expression. In doing so, the Mathematica program is used in order to investigate the impact of Rabinowitsch parameter $K$, Prandlt number $P r$, heat source $Q$, electroosmotic parameter $m$, volume fraction $C$, Grashof number $G r$, maximum electroosmotic velocity $\mathbf{U}_{\mathrm{HS}}$ and radius of the channel for elasticity $\alpha^{\prime}$ on the shear stress $\tau_{\mathrm{xy}}$, axial velocity $U(y)$, pressure gradient $\frac{\mathrm{dp}}{\mathrm{dx}}$ and pressure rise $\mathbf{p}$. A graphical comparison is also set to compare between pseudoplastic and dilatant fluids.

Figures 2-9 are plotted to investigate the impact of $\mathbf{U}_{\mathrm{HS}}, C, G r, m, K$ and $\alpha^{\prime}$ on $\tau_{\mathrm{xy}}$ for sundry values of the parameters of interest. It is observed from Figs. $2-7$ that the Rabinowitsch shear stress improves prominently with increasing all the parameters even with increasing the curviness of the conduit in both the lower and upper halves of the channel. Figures 8 and 9 demonstrate a comparison between the impact of pseudoplasticity and dilatation on the shear stress profile through $x$ and $y$ axes, respectively. It is notable form the latter figures that for pseudoplastic fluid, $\tau_{\mathrm{xy}}$ is enhanced along the conduit through the $x$-axis, whereas for the case of dilatant fluids, a reverse effect is observed. It is also seen that $\tau_{\mathrm{xy}}$ behaves differently along the $y$-axis where it is seen that for the pseudoplastic fluids, $\tau_{\mathrm{xy}}$ decays near the lower wall of the channel and improves with an increase in the curviness of the channel. An exact opposite behaviour is seen for dilatant fluids as seen in Fig. 9.

Figures 10-16 illustrate the impact of $K, \mathbf{U}_{\mathrm{HS}}, G r, C, m$ and $\alpha^{\prime}$ on $U(y)$ for various values of the pertinent parameters. It is noticed that $K, \mathbf{U}_{\mathrm{HS}}$ and $\alpha^{\prime}$ play a distinguished role in lessening the fluid velocity as seen in Figs. 10, 11 and 15. It is also depicted that $G r, C$ and $m$ disturb the velocity profile significantly as observed in Figs. 12-14. It is noticed that the latter parameters have barely an effect on $U(y)$ near the walls of the channel, whereas they enhance the flow in the centre part of the channel. It is generally noticed that $U(y)$ has a parabolic shape along the conduit for all the parameters under consideration. Figure 16 is plotted to spot the difference in the behaviour of $U(y)$ for pseudoplastic and dilated fluids. It is demonstrated that for pseudoplastic fluids, $U(y)$ is not disturbed at all near the walls of the conduit, whereas it is noticed that for dilated fluids, the flow is decelerated at the centre of the channel.

Figures 17-22 are prepared in order to see the behaviour of $\frac{\mathrm{dp}}{\mathrm{dx}}$ along the axis of the conduit under the effect of $K, C, \mathbf{U}_{\mathrm{HS}}, G r, m$ and $\alpha^{\prime}$. It is seen that $K, C, m$ and $\alpha^{\prime}$ serve to reduce $\frac{\mathrm{dp}}{\mathrm{dx}}$ for all values of the pertinent parameters as noticed in Figs. 17, 18, 21 and 22. It is also noticed from Figs. 19 and 20 that $\frac{\mathrm{dp}}{\mathrm{dx}}$ grows for greater values of $\mathbf{U}_{\mathrm{HS}}$ and $G r$. It is also observed that for $x[?][0,2]$ and $[3.9,6]$ the pressure gradient is small and that the large pressure gradient occurs for $x[?][2.1,4]$.

Figures 23-28 are prepared in order to spot the variation ofp that is portrayed against the dimensionless time-averaged flux across one wavelength, $Q$, for several values of the parameters under consideration. The contributions of $K$, Grand $m$ for $\mathbf{p}$ are displayed in Figs. 23, 25 and 26 where it is noticed that $\mathbf{p}$ decays near the lower wall of the channel and grows afterwards with an increase in the channel curviness. It is 
also shown from Figs. 24 and 27 that pattains smaller values as the channel curviness increases away from the wall of the conduit. Last but not least, Fig. 28 displays the behaviour of $\mathbf{p}$ in case of dilatation and pseudoplasticity of fluids. It is seen that $\mathbf{p}$ is generally higher for dilated fluids than that of pseudoplastic ones. It is also observed that pdecreases for dilated fluids all way long, whereas it decreases for pseudoplastic fluids only until a specific value $(Q=1)$ away from the wall from which the behaviour is reversed.

\section{Biomedical application of the problem}

Shear stress of fluid circulation is an important diagnostic aspect for evaluating the properties of blood supply through the arteries. The evolution of shear stress in the stenosis system, combined with the dynamic rheology of the blood, describes the reduction of the circular region of the system over time. Wall shear stress plays a significant part in reshaping the arterial wall which can contribute to arterial thickening. Table $\mathbf{1}$ illustrates the non-dimensional shear stresses of Rabinowitsch fluid, $\tau$, through artery for various values of the hematocrit, $C$, for diseased blood. It is noticed that the as $\mathrm{C}$ increases, $\tau$ increases.

\begin{tabular}{|c|c|c|c|c|c|c|}
\hline$x$ & $\begin{array}{l}\text { Shear stress } \\
\text { of Rabinow- } \\
\text { itsch fluid } \\
\tau\end{array}$ & $\begin{array}{l}\text { Shear stress } \\
\text { of Rabinow- } \\
\text { itsch fluid } \\
\tau\end{array}$ & $\begin{array}{l}\text { Shear stress } \\
\text { of Rabinow- } \\
\text { itsch fluid } \\
\tau\end{array}$ & $\begin{array}{l}\text { Shear stress } \\
\text { of Rabinow- } \\
\text { itsch fluid } \\
\tau\end{array}$ & $\begin{array}{l}\text { Shear stress } \\
\text { of Rabinow- } \\
\text { itsch fluid } \\
\tau\end{array}$ & $\begin{array}{l}\text { Shear stress } \\
\text { of Rabinow- } \\
\text { itsch fluid } \\
\tau\end{array}$ \\
\hline & $C=0.248$ & $C=0.28$ & $C=0.426$ & $C=0.4325$ & $C=0.4331$ & $C=0.632$ \\
\hline & $\begin{array}{l}\text { Hb SS (Sickle } \\
\text { Cell) }\end{array}$ & $\begin{array}{l}\text { Plasma Cell } \\
\text { dyscrasias }\end{array}$ & Normal blood & $\begin{array}{l}\text { Hypertension } \\
\text { (controlled) }\end{array}$ & $\begin{array}{l}\text { Hypertension } \\
\text { (uncontrolled) }\end{array}$ & Polycythemia \\
\hline 0. & 0.508917 & 0.538364 & 0.707973 & 0.717319 & 0.718192 & 1.15146 \\
\hline 0.2 & 0.505563 & 0.534945 & 0.704064 & 0.713379 & 0.714249 & 1.14586 \\
\hline 0.4 & 0.495578 & 0.524771 & 0.69247 & 0.701695 & 0.702557 & 1.12931 \\
\hline 0.6 & 0.479179 & 0.508091 & 0.673581 & 0.682663 & 0.683511 & 1.10248 \\
\hline 0.8 & 0.456697 & 0.485281 & 0.64801 & 0.656909 & 0.657739 & 1.0665 \\
\hline 1. & 0.428523 & 0.456801 & 0.616547 & 0.625236 & 0.626047 & 1.02282 \\
\hline 1.2 & 0.395056 & 0.423142 & 0.580099 & 0.588575 & 0.589366 & 0.973144 \\
\hline 1.4 & 0.35665 & 0.384766 & 0.539639 & 0.54792 & 0.548692 & 0.919356 \\
\hline 1.6 & 0.313594 & 0.34209 & 0.496165 & 0.504294 & 0.505052 & 0.86342 \\
\hline 1.8 & 0.266209 & 0.295542 & 0.450704 & 0.458753 & 0.459502 & 0.807327 \\
\hline 2. & 0.215192 & 0.245805 & 0.404386 & 0.41245 & 0.4132 & 0.753059 \\
\hline 2.2 & 0.162415 & 0.194396 & 0.358613 & 0.3668 & 0.367561 & 0.702604 \\
\hline 2.4 & 0.111854 & 0.144497 & 0.315318 & 0.323729 & 0.324509 & 0.657972 \\
\hline 2.6 & 0.0690173 & 0.101038 & 0.277209 & 0.285898 & 0.286704 & 0.621209 \\
\hline 2.8 & 0.038254 & 0.0688821 & 0.24769 & 0.256637 & 0.257466 & 0.594302 \\
\hline 3. & 0.0213037 & 0.0508044 & 0.23019 & 0.2393 & 0.240144 & 0.578956 \\
\hline 3.2 & 0.0183903 & 0.0476728 & 0.227071 & 0.236211 & 0.237058 & 0.576266 \\
\hline 3.4 & 0.029497 & 0.0595737 & 0.238779 & 0.247809 & 0.248646 & 0.586434 \\
\hline 3.6 & 0.0546015 & 0.0860756 & 0.26368 & 0.272484 & 0.2733 & 0.608713 \\
\hline 3.8 & 0.0927918 & 0.125329 & 0.298654 & 0.307178 & 0.307969 & 0.641609 \\
\hline 4. & 0.140811 & 0.173205 & 0.340168 & 0.348438 & 0.349206 & 0.683216 \\
\hline 4.2 & 0.19328 & 0.22449 & 0.385186 & 0.393288 & 0.394041 & 0.731496 \\
\hline 4.4 & 0.245362 & 0.275183 & 0.431472 & 0.439514 & 0.440263 & 0.78442 \\
\hline 4.6 & 0.294386 & 0.323171 & 0.477437 & 0.485523 & 0.486276 & 0.839995 \\
\hline 4.8 & 0.339291 & 0.367516 & 0.521865 & 0.530076 & 0.530841 & 0.896238 \\
\hline 5. & 0.379664 & 0.407729 & 0.563701 & 0.572092 & 0.572875 & 0.95116 \\
\hline
\end{tabular}

Table 1 : Rabinowitsch shear stress through an artery for various values $C$.

10 Deductions 
In this article, the impact of Rabinowitsch suspension fluid through elastic walls with heat transfer under the effect of the electroosmotic forces is investigated. The solutions of the fluid model are achieved by taking a long wavelength approximation. A comparison is set between the effect of pseudoplasticity and dilatation on the behaviour of shear stress, axial velocity and pressure rise. The impact of all the pertinent parameters are discussed graphically. The main observations are as follows:

1. Unlike the effect of the radius of the channel for elasticity on the shear stress, it tends to reduce the axial velocity, pressure gradient and pressure rise.

2. The volume fraction boosts the shear stress and the axial velocity, whereas the effect is totally reversed with the pressure gradient and pressure rise.

3. Grashof number accelerates the flow and increases shear stresses along with the pressure gradient.

4. The maximum axial velocity takes place at the centre of the conduit.

5. The maximum electroosmotic velocity boosts the shear stress and pressure gradient but reduces the axial velocity.

6. The influence of the Rabinowitsch and electroosmotic parameters is to enhance the shear stress, whereas their effect is totally reversed for the pressure gradient.

7. The current model reduces to the case of dilatant fluid for $K<0$, pseudoplastic fluid for $K>0$.

Declaration of interests

Authors report no conflict of interest.

Acknowledgment

Figure $1 b$ is used by courtesy of Encyclopaedia Britannica.

\section{References}

[1] Noreen SherAkbar and Adil WahidButt Heat transfer analysis of Rabinowitsch fluid flow due to metachronal wave of cilia, Results in Physics, Volume 5, 2015, Pages 92-98.

[2] B.K. Singh1 and Dr. U.P. Singh, Analysis of Peristaltic Flow in a Tube: Rabinowitsch Fluid Model, International Journal of Fluids Engineering. ISSN 0974-3138 Volume 6, Number 1 (2014), pp. 1-8.

[3] Vaidya, H., Rajashekhar, C., Manjunatha, G., \& Prasad, K. V. (2019). Peristaltic mechanism of a Rabinowitsch fluid in an inclined channel with complaint wall and variable liquid properties. Journal of the Brazilian Society of Mechanical Sciences and Engineering, 41(1), [52]. https://doi.org/10.1007/s40430-0181543-4.

[4] H. Sadaf and S. Nadeem, Analysis of Combined Convective and Viscous Dissipation Effects for Peristaltic Flow of Rabinowitsch Fluid Model, Journal of Bionic Engineering 14(1):182-190.

[5] R. Choudhari et al , analysis of peristaltic flow of rabinowitsch fluid in a non-uniform channel: analytical approach, Latin American applied research Pesquisa aplicada latino americana (Investigacion aplicada latinoamericana), 50(03):151-158

[6] K. S. Mekheimer, A. Z. Zaher, and W. M. Hasona, \Entropy of ac electro-kinetics for blood mediated gold or copper nanoparticles as a drug agent for thermotherapy of oncology, "Chinese Journal of Physics, vol. 65 , pp. $123\{138,2020$.

[7] K. S. Mekheimer, A. Z. Zaher, and R. E. Abo-Elkhair, \Electro-magnetohydrodynamic oscillatory flow of a dielectric fluid through a porous medium with heat transfer: Brinkman model,"BioNanoScience, vol. 8, pp. $596\{608,2018$.

[8] K. S. Mekheimer, R. E. Abo-Elkhair, and A. M. A. Moawad, \Electro-osmotic flow of non-newtonian biofluids through wavy micro-concentric tubes," BioNanoScience, 8 (2018),723.

[9] F. F. Reuss, Mémoires de la Société impériale des naturalistes de Moscou," Imperial Moscow University, vol. 2, pp. $327\{337,1809$. 
[10] KS Mekheimer, AZ Zaher, AI Abdellateef, Entropy hemodynamics particle-fluid suspension model through eccentric catheterization for time-variant stenotic arterial wall: Catheter injection- IJGMM, 2019 (16), 1950164-496

[11] Zeeshan A,Ijaz N, Bhatti MM (2018) Flow analysis of particulate suspension on an asymmetric peristaltic motion in a curved configuration with heat and mass transfer. Mech Ind 19(4):401

[12] SI Abdelsalam, K, Vafai (2017) Particulate suspension effect on peristaltically induced unsteady pulsatile flow in a narrow artery: blood flow model. Math Biosci 283:91-105.

[13] Khan, A.A., Tariq, H. Influence of wall properties on the peristaltic flow of a dusty Walter's B fluid. J Braz. Soc. Mech. Sci. Eng. 40, 368 (2018). https://doi.org/10.1007/s40430-018-1285-3

[14] S. U. S Choi., "Enhancing Thermal Conductivity of Fluids with Nanoparticles," Developments and Applications of Non-Newtonian Flows, D. A. Siginer and H. P. Wang, eds., ASME, New York, FED-231/MD66, 1995, pp. 99- 105 .

[15] H. Sadaf, S. I. Abdelsalam, 'Adverse effects of hybrid nanofluid in a wavy nonuniform annulus with convective boundary conditions' RSC Advances, Vol. 10, pp. 15035-15043 (2019).

[16] M. M. Bhatti, R. Ellahi, A. Zeeshan, M. Marin, S. I. Abdelsalam, 'Swimming of motile gyrotactic microorganisms and movement of nanoparticles in blood flow through anisotropically tapered arteries' Frontiers in Physics, Vol. 8, Article 95, pp. 1-9 (2020).

[17] S. I. Abdelsalam, M. M. Bhatti, 'Anomalous reactivity of thermo-bioconvective nanofluid towards oxytactic microorganisms' Applied Mathematics and Mechanics, DOI.org/10.1007/s10483-020-2609-6, pp. 114(2020).

[18] Kh.S. Mekheimer, W.M. Hasona, R.E. Abo-Elkhair and A.Z. Zaher, Peristaltic blood flow with gold nanoparticles as a third grade nanofluid in catheter: Application of cancer therapy, Physics Letters A. 382 (2018) 85-93.

[19] M. Sohail, R. Naz, S. I. Abdelsalam, 'On the onset of entropy generation for a nanofluid with thermal radiation and gyrotactic microorganisms through 3D flows' Physica Scripta, Vol. 95, pp. 045206 [12 pages] (2020).

[20] S. I. Abdelsalam, M. M. Bhatti, The study of non-Newtonian nanofluid with Hall and ion slip effects on peristaltically induced motion in a non-uniform channel, RSC Advances. 8: 7904-7915 (2018).

[21] Taha Sochi, The flow of Newtonian and Power law fluids in elastic tubes, Intern.Journal of Nonlinear Mechanics, Vol.67(2014), pp. 245-250.

[22] A. Shankar and G. Jayaraman, Non-linear analysis of oscillatory flow in the annulus of an elastic tube: Applications to catheterized artery". Physics of Fluids, Vol. 13(10) (2001), pp. 2901-2911. https://doi.org/10.1063/1.1389285.

[23] G, Pedrizzetti, Fluid flow in a tube with elastic membrane insertion, Journal of Fluid Mechanics, Vol. 375, (1998) pp. 39-64. https://doi.org/ 10.1017/S0022112098002316.

[24] S.I. Rubinow, J.B. Keller, Flow of a viscous fluid through an elastic tube with applications to blood flow, J Theor Biol. 1972 (35) 299-313.

[25] N. Ijaz, A. Zeeshan and, M.M. Bhatti, Peristaltic propulsion of particulate non-Newtonian Ree-Eyring fluid in a duct through constant magnetic field, Alexandria Engineering Journal (2018) 57, 1055-1060.

\section{Hosted file}

image3.emf available at https://authorea.com/users/364006/articles/484593-leveraging-

elasticity-to-uncover-the-role-of-rabinowitsch-suspension-through-a-wavelike-conduit 
Figure 2: Display of shear stress profile for different values of $\mathbf{U}_{\mathrm{HS}}$.

\section{Hosted file}

image4.emf available at https://authorea.com/users/364006/articles/484593-leveragingelasticity-to-uncover-the-role-of-rabinowitsch-suspension-through-a-wavelike-conduit

Figure 3: Display of shear stress profile for different values of $C$.

\section{Hosted file}

image5.emf available at https://authorea.com/users/364006/articles/484593-leveragingelasticity-to-uncover-the-role-of-rabinowitsch-suspension-through-a-wavelike-conduit

Figure 4: Display of shear stress profile for different values of $G r$.

\section{Hosted file}

image6.emf available at https://authorea.com/users/364006/articles/484593-leveragingelasticity-to-uncover-the-role-of-rabinowitsch-suspension-through-a-wavelike-conduit

Figure 5: Display of shear stress profile for different values of $m$.

\section{Hosted file}

image7.emf available at https://authorea.com/users/364006/articles/484593-leveragingelasticity-to-uncover-the-role-of-rabinowitsch-suspension-through-a-wavelike-conduit

Figure 6: Display of shear stress profile for different values of $K$.

\section{Hosted file}

image8.emf available at https://authorea.com/users/364006/articles/484593-leveragingelasticity-to-uncover-the-role-of-rabinowitsch-suspension-through-a-wavelike-conduit

Figure 7: Display of shear stress profile for different values of $\alpha{ }^{\prime}$.

\section{Hosted file}

image9.emf available at https://authorea.com/users/364006/articles/484593-leveragingelasticity-to-uncover-the-role-of-rabinowitsch-suspension-through-a-wavelike-conduit

Figure 8: Display of shear stress profile via $x$ for pseudoplastic and dilatant fluids.

\section{Hosted file}

image10.emf available at https://authorea.com/users/364006/articles/484593-leveragingelasticity-to-uncover-the-role-of-rabinowitsch-suspension-through-a-wavelike-conduit

Figure 9: Display of shear stress profile via $y$ for pseudoplastic and dilatant fluids.

\section{Hosted file}

image11.emf available at https://authorea.com/users/364006/articles/484593-leveragingelasticity-to-uncover-the-role-of-rabinowitsch-suspension-through-a-wavelike-conduit

Figure 10: Display of axial velocity for different values of $K$.

\section{Hosted file}

image12.emf available at https://authorea.com/users/364006/articles/484593-leveragingelasticity-to-uncover-the-role-of-rabinowitsch-suspension-through-a-wavelike-conduit

Figure 11: Display of axial velocity for different values of $\mathbf{U}_{\mathrm{HS}}$. 


\section{Hosted file}

image13.emf available at https://authorea.com/users/364006/articles/484593-leveragingelasticity-to-uncover-the-role-of-rabinowitsch-suspension-through-a-wavelike-conduit

Figure 12: Display of axial velocity for different values of $G r$.

\section{Hosted file}

image14.emf available at https://authorea.com/users/364006/articles/484593-leveragingelasticity-to-uncover-the-role-of-rabinowitsch-suspension-through-a-wavelike-conduit

Figure 13: Display of axial velocity for different values of $C$.

\section{Hosted file}

image15.emf available at https://authorea.com/users/364006/articles/484593-leveragingelasticity-to-uncover-the-role-of-rabinowitsch-suspension-through-a-wavelike-conduit

Figure 14: Display of axial velocity for different values of $m$.

\section{Hosted file}

image16.emf available at https://authorea.com/users/364006/articles/484593-leveragingelasticity-to-uncover-the-role-of-rabinowitsch-suspension-through-a-wavelike-conduit

Figure 15: Display of axial velocity for different values of $\alpha$ '.

\section{Hosted file}

image17.emf available at https://authorea.com/users/364006/articles/484593-leveragingelasticity-to-uncover-the-role-of-rabinowitsch-suspension-through-a-wavelike-conduit

Figure 16: Display of axial velocity for pseudoplastic and dilatant fluids.

\section{Hosted file}

image18.emf available at https://authorea.com/users/364006/articles/484593-leveragingelasticity-to-uncover-the-role-of-rabinowitsch-suspension-through-a-wavelike-conduit

Figure 17: Display of pressure gradient for different values of $K$.

\section{Hosted file}

image19.emf available at https://authorea.com/users/364006/articles/484593-leveragingelasticity-to-uncover-the-role-of-rabinowitsch-suspension-through-a-wavelike-conduit

Figure 18: Display of pressure gradient for different values of $C$.

\section{Hosted file}

image20.emf available at https://authorea.com/users/364006/articles/484593-leveragingelasticity-to-uncover-the-role-of-rabinowitsch-suspension-through-a-wavelike-conduit

Figure 19: Display of pressure gradient for different values of $\mathbf{U}_{\mathrm{HS}}$.

\section{Hosted file}

image21.emf available at https://authorea.com/users/364006/articles/484593-leveragingelasticity-to-uncover-the-role-of-rabinowitsch-suspension-through-a-wavelike-conduit

Figure 20: Display of pressure gradient for different values of $G r$.

\section{Hosted file}


image22.emf available at https://authorea.com/users/364006/articles/484593-leveragingelasticity-to-uncover-the-role-of-rabinowitsch-suspension-through-a-wavelike-conduit

Figure 21: Display of pressure gradient for different values of $m$.

\section{Hosted file}

image23.emf available at https://authorea.com/users/364006/articles/484593-leveragingelasticity-to-uncover-the-role-of-rabinowitsch-suspension-through-a-wavelike-conduit

Figure 22: Display of pressure gradient for different values of $\alpha^{\prime}$.

\section{Hosted file}

image24.emf available at https://authorea.com/users/364006/articles/484593-leveragingelasticity-to-uncover-the-role-of-rabinowitsch-suspension-through-a-wavelike-conduit

Figure 23: Display of pressure rise vs volume flow rate for different values of $K$.

\section{Hosted file}

image25.emf available at https://authorea.com/users/364006/articles/484593-leveragingelasticity-to-uncover-the-role-of-rabinowitsch-suspension-through-a-wavelike-conduit

Figure 24: Display of pressure rise vs volume flow rate for different values of $C$.

\section{Hosted file}

image26.emf available at https://authorea.com/users/364006/articles/484593-leveragingelasticity-to-uncover-the-role-of-rabinowitsch-suspension-through-a-wavelike-conduit

Figure 25: Display of pressure rise vs volume flow rate for different values of $G r$.

\section{Hosted file}

image27.emf available at https://authorea.com/users/364006/articles/484593-leveragingelasticity-to-uncover-the-role-of-rabinowitsch-suspension-through-a-wavelike-conduit

Figure 26: Display of pressure rise vs volume flow rate for different values of $m$.

\section{Hosted file}

image28.emf available at https://authorea.com/users/364006/articles/484593-leveragingelasticity-to-uncover-the-role-of-rabinowitsch-suspension-through-a-wavelike-conduit

Figure 27: Display of pressure rise vs volume flow rate for different values of $\alpha^{\prime}$.

\section{Hosted file}

image29.emf available at https://authorea.com/users/364006/articles/484593-leveragingelasticity-to-uncover-the-role-of-rabinowitsch-suspension-through-a-wavelike-conduit

Figure 28: Display of pressure rise vs volume flow rate for pseudoplastic and dilatant fluids. 